\title{
Information about management of chronic drug therapies prescribed at hospital discharge: does it affect patients' knowledge and self-confidence?
}

\author{
Claudia Pileggi ${ }^{1}$, Emilia Caligiuri ${ }^{1}$, Carmelo G. A. Nobile ${ }^{2}$ and Maria Pavia ${ }^{1 *}$
}

\begin{abstract}
Background: Hospital stay represents the opportunity for a change of therapy, about which patients may not know indications, contraindications, and mode of administration, which may lead to dosing errors, drug interactions, side effects, etc. It is therefore vital to communicate appropriate information to the discharged patient with a new prescription drug. The purpose of the study was to evaluate: 1) how communication about new chronic therapies is managed at hospital discharge and what kind of information is provided to patients; 2) to what extent patients are aware and confident in the management of these medications; 3) whether the way communication is provided affects patients' awareness and self-confidence in the management of these therapies.

Methods: Participants were adult patients who were prescribed at least one new chronic medication at hospital discharge. A telephone interview after hospital discharge was performed to assess whether or not hospital healthcare personnel had given information about prescribed therapies and which aspects of therapies had been object of information.

Results: Five hundred thirty patients were interviewed. $67.7 \%$ reported having received counseling by the hospital physician, while $32.3 \%$ by discharge form. Basic information on treatment was provided to the great majority of patients, whereas only few patients reported to have been informed about eventual side effects and related behavior in case of side effects.

Conclusions: Several aspects of patients' knowledge and self-confidence on long term medications prescribed at hospital discharge need to be improved and the way communication is provided has a crucial role in the empowerment of patients in the management of these medications.
\end{abstract}

Keywords: Chronic drug therapies, Discharge counseling, Patient safety, Continuity of care

\section{Background}

Chronic conditions are health problems that require ongoing management over a period of years or decades, and cover a wide range of conditions that go beyond the conventional definition of chronic illness, such as cardiovascular and respiratory diseases or diabetes. They also extend to some persistent communicable diseases

\footnotetext{
*Correspondence: pavia@unicz.it

'Department of Health Sciences, University of Catanzaro "Magna Græcia", Via

Tommaso Campanella, 88100 Catanzaro, Italy

Full list of author information is available at the end of the article
}

(e.g. HIV/AIDS), to certain mental disorders (e.g. depression), and to cancer [1].

Advances in healthcare have led to growing numbers of people surviving with chronic illness. At the same time, the significant growth of elderly population led to the emergence of new needs associated with increasing number of those with chronic health problems because of accumulated exposure to chronic disease risk factors over their lifetime. The common theme of chronic illness is that these conditions require complex models of care, over an extended time period that involves coordinated inputs from a wide range of health professionals 
and access to essential medicines and monitoring systems, all of which need to be optimally embedded within a system that promotes patient empowerment.

Several theoretical frameworks and delivery models were designed to approach patients with chronic diseases and various levels of healthcare need [2-6]. Perhaps the most influential framework has been the Chronic Care Model (CCM) developed by Wagner and colleagues [7] and adapted by WHO [8] in a global perspective. It was based on the premise that high-quality chronic care is characterized by productive interactions between the practice team and patients, involving assessment, self-management support, optimization of therapy and follow-up.

A key role in the appropriate management of chronic diseases care is played directly by the patient him/herself, through effective adherence to a complex therapeutic pathway that mostly relies on chronic assumption of drugs, lifestyle changes, and follow-up controls. Similarly, patients play a substantial role in the safety of this process of care, by helping to reach an accurate diagnosis, by ensuring that treatment is appropriately administered, monitored and adhered to, by identifying side effects or adverse events and taking appropriate action [9]. The safety and effectiveness of hospital clinical pathways has long been studied and process and outcome indicators have been developed to monitor hospital performance [10-13], whereas less attention has been devoted to outpatient processes of care, particularly when therapies are mostly in charge of patients themselves.

In patients with chronic diseases, hospital stay frequently represents the opportunity for a prescription of new drugs, about which patients may not know indications, contraindications, and mode of administration, which may lead to dosing errors, drug interactions, side effects, but also failure to achieve the expected therapeutic targets. Moreover, it has been hypothesized that primary non-adherence, defined as failure to fulfill a newly prescribed medication, could be related to poor communication between the inpatient medical team and the patient, as well as with the primary care physician (PCP) [14].

At the time of discharge, the patient may obtain information and data about new prescribed medication from various sources such as counseling or written information $[15,16]$, but doctors, nurses and pharmacists are the main source of this information [8]. It is therefore vital to communicate appropriate information to the patient discharged with a new prescription drug [9]. Proper notification to the person increases the degree of adherence to treatment $[17,18]$, which, despite being influenced by psychological, social, cultural and environmental factors, is seriously undermined if the patient has not been provided the necessary information or if it has been perceived in a distorted manner [19].

Therefore, the purposes of the study were to evaluate: 1) how communication about new chronic therapies is managed at hospital discharge and what kind of information is provided to patients; 2) to what extent patients are aware and confident in the management of these medications; 3 ) whether the way communication is provided affects patients' awareness and self confidence in the management of these therapies.

\section{Methods}

The study was designed as cross-sectional. The eligible population was selected among patients admitted for ordinary hospitalization in one academic hospital (n. 250 beds) and one non-academic hospital (n. 450 beds) located in Catanzaro, Italy. The selection process of eligible patients consisted of two phases. In the first phase, that was carried out during hospital stay, potentially eligible patients had to fulfill the following inclusion criteria: 1) age $>18$; 2) admission in a medical ward (Cardiology, Internal Medicine, Nephrology, Hepatology, Respiratory Diseases, Geriatrics, Metabolic Diseases) at least $48 \mathrm{~h}$ before selection. All of these patients were invited to participate in the study during hospitalization by physicians not involved in clinical care, that explained them the purpose and the design of the study, and a written informed consent to participation was asked to those who were willing to take part in the study. In the second phase of the selection process the medical records of patients that had provided informed consent were reviewed after patients' discharge in order to select those who were prescribed, at time of discharge, at least one new chronic medication, that was not present in their treatment upon admission. A medication was considered chronic if prescribed for 30 days or longer. Patients who were prescribed dose modifications of existing drugs in the treatment or substitution by another equivalent drug and those that were potentially suffering of a cognitive impairment, as shown by anamnestic data or psychological/psychiatric consultations reported in the medical record, were excluded from the study.

Consultation of medical records enabled collection of further information on hospitalization (ward and diagnosis at admission and at discharge).

Patients included in the study after the two-phases selection process underwent a structured telephone interview within 3 weeks after hospital discharge.

In the telephone interview, if more than one new medication was prescribed, information was collected on the drug that had the longer length of prescription. It was first asked whether or not hospital healthcare personnel had given information about prescribed 
therapies at discharge, and separated questions were asked according to source of information. In patients who reported to have been informed by hospital healthcare personnel, an in depth interview was performed to investigate which aspects of therapies had been object of information to patients: reasons for the prescription of the new drug, mode (dosage and route of administration) and time of drug intake, duration of treatment, necessity and frequency of periodic controls, behaviour in case of forgotten medication intake or in case of having taken the wrong dose of medication, necessity to avoid concomitant use of the drug with other drugs and/or food, side effects and behavior in case of occurrence of side effects, possibility of discontinuing therapy as a consequence of medical condition improvement and consequences of not taking the therapy. In those patients who reported to have not been informed by hospital healthcare personnel about prescribed medications eventual other sources of information were retrieved (PCP, private specialist, pharmacist, discharge form, internet, other patients taking the same medication, etc.).

Moreover, in all participant patients, regardless of the source of information, medication knowledge and patient perceived self-confidence were assessed by the questions drawn from the Okere-Renier Survey instrument [20]. Finally, the need for more information and the favourite person to contact in case of doubt about therapy, were also investigated.

A sample size of about 500 patients was calculated to have a $80 \%$ power and an $\alpha$ of 0.05 to detect a $15 \%$ difference in knowledge about new medications between patients who received counseling by healthcare personnel as compared to discharge form.

The study was conducted from January 2012 to February 2013.

\section{Statistical analysis}

Data were analyzed using the Stata software program [21]. Continuous variables were compared using the two-tailed Student's t test. Categorical variables were compared using the Pearson's chi-square test or twotailed Fisher's exact test, when appropriate. One model was developed using multiple logistic regression analysis to identify the variables related to the way information was provided at discharge $(0=$ letter of hospital discharge, $1=$ hospital specialist). The explanatory variables included in model were the following: $\operatorname{sex}(0=$ male, $1=$ female), hospital $(0=$ academic, $1=$ non academic $)$, age groups $(0=<65,1=\geq 65)$, marital status $(0=$ other, $1=$ married), working activity $(0=$ unemployed or retired, 1 $=$ employed $)$, discharge ward $(0=$ general medicine, $1=$ specialist care), number of new prescription drugs $(0=$ one prescription, $1=>$ one prescription), need for more information about therapy $(0=$ no, $1=$ yes $)$, knowledge about behaviour in case of having taken the wrong dose of medication $(0=$ no, $1=$ yes $)$, knowledge about duration of treatment with new medication $(0=$ no, $1=$ yes $)$, knowledge about possible side effects $(0=$ no, $1=$ yes $)$, knowledge about behaviour in case of having forgotten medication intake $(0=$ no, $1=$ yes $)$, favourite person to contact in case of doubt about therapy $(0=\mathrm{PCP}, 1=$ hospital or private specialist). Adjusted odds ratio (OR) and 95\% confidence intervals (CI) were calculated.

The study protocol was approved by the Ethics Committee of the "Mater Domini" Hospital of Catanzaro (Italy) (15/12/2011).

\section{Results}

During the study period, 558 patients were discharged with a prescription of a new drug. Of these, 12 patients (2.1\%) refused to be interviewed, $4(0.7 \%)$ were excluded because they were re-hospitalized, $1(0.2 \%)$ because of serious health conditions, and $11(2 \%)$ were not available after 10 calls. Therefore the results are reported for 530 patients, for a $95 \%$ response rate, that were interviewed within 3 weeks after discharge. The average age of the participants was 63.3 years $( \pm 13.7$ years), men constituted $57 \%$ of the sample. The majority of patients were married $(77.4 \%)$ and $24.2 \%$ had acquired more than 8 years of education. $76.8 \%$ of the patients were unemployed or retired.

Hospital admission was related to cardiovascular diseases in $47.5 \%$ of patients, and to liver and kidney diseases in $15.3 \%$ and $11.2 \%$ of patients, respectively. Other diagnoses were involved in $26 \%$ of the admissions.

$67.7 \%$ reported having received counseling about their medications by the hospital physician at the moment of discharge, while for the remaining $32.3 \%$ the only source of information was the discharge form. Among these, after discharge, 6 patients sought further clarification about new prescribed drugs to PCPs, 2 patients to private specialist physicians and 2 to pharmacists. Table 1 reports the information about new prescribed drug(s) provided to patients by hospital physicians at discharge. Basic information on treatment, such as reason, dosage and route of administration, time and duration of treatment, necessity and frequency of controls, was provided to the great majority of patients, just over half received information about the consequences of not taking the therapy and about avoiding concomitant use of the drug with other drugs and/or foods, whereas only few patients reported to have been informed about eventual side effects and related behavior in case of side effects, as well as in case of having forgotten or having taken the wrong dose of medication. Table 2 reports general characteristics of patients, actual knowledge about new prescriptions received and disaggregated knowledge according to 
Table 1 Information about new prescribed drug provided to patients by hospital physician at discharge

\begin{tabular}{lcc}
\hline Characteristic & Number & Percent \\
\hline Reasons for the prescription of new drugs & 320 & 359 \\
Mode of drug intake (dosage and route of administration) & 358 & 100 \\
Timing of drug intake & 291 & 99.7 \\
Duration of treatment & 324 & 81 \\
Necessity of periodic controls & 317 & 34 \\
Frequency of periodic controls & 15 \\
Behavior in case of forgotten drug intake & 205 \\
Behavior in case of having taken the wrong dose of medication & 35 \\
Avoid concomitant use of the drug with other drugs and / or foods & 29 \\
Side effects & 46.2 \\
Behavior in case of occurrence of side effects & 46 \\
Possibility of discontinuing therapy as a consequence of improvement & 207 \\
Consequences of not taking the therapy & 57.1 \\
\hline
\end{tabular}

source of information (hospital physician at discharge or discharge form). Virtually all patients are aware of mode, time and duration of administration of the new prescribed drug, whereas lack of knowledge is related to behaviors to have when one forgets or accidentally takes wrong doses of the new drug; moreover, among those who reported to know how to behave, the most frequently reported response was to ask to the physician, particularly the PCP (54.9\%). Even a lower percentage of patients $(8.5 \%)$ is aware of possible side effects, whereas $41.5 \%$ reported to need more information about the new prescription, particularly about duration (33\%), side effects $(26.8 \%)$, and mode of administration (21.4\%).

At univariate analysis, patients who correctly reported the duration of therapy, who were confident about the behavior to have in case they forget or take a wrong dose of the prescribed drug were significantly more likely to have been informed by the hospital physician at discharge, as well as females, those who were discharged by an academic hospital and those who do not feel they need more information about the new prescribed drug. As expected, the favourite person to contact in case of doubt about therapy was significantly more likely to be the hospital or private specialist (Table 2). These results were substantially confirmed by multivariate analysis, except for the knowledge about behavior in case of having forgotten medication intake (Table 3).

\section{Discussion}

Although transitions across health care settings are recognized to be vulnerable periods for the correct adherence to newly prescribed therapies, only few studies have addressed in depth how to overcome post hospital discharge medication problems, particularly for patients who are prescribed new drugs in the hospital and have to manage chronic therapies at home.

Our study has tried to explore one of the crucial factors involved in the correct continuity of care after hospital discharge, that is communication on new drug chronic therapies prescribed at hospital discharge.

The first research question investigated how communication about new chronic therapies is managed at hospital discharge and what kind of information is provided to patients and the results revealed that there are only two ways information is provided: direct counselling by the hospital physician in about two thirds of patients and from the discharge form in the remaining cases. It should be noted that in Italy, although nurses are an important source of information, generally physicians are reluctant to rely on other healthcare professionals (nurses, pharmacists) to convey medication related information. This may be because physicians consider themselves to be the primary source of patient information and, on the other hand, patients prefer to be informed by physicians, as in other countries [22, 23].

About the finding that one third of discharged patients did not receive any counselling about new prescribed long term drugs, it should be noted that the discharge form is a compulsory part of the discharge process in Italy including information about the admission, diagnosis at discharge, comorbidities and the list of prescribed medications. The dose and the mode of intake of each medicine are noted along with the changes in medication after admission, whereas no information is reported about medicines side effects or interaction. The discharge form is given to the patient at discharge and a copy is addressed to the PCP that will take care of the discharged patient. This result is a concern, as already highlighted by Toren et al., that found that only $40 \%$ of 
Table 2 Distribution of source of information about the new prescription drug according to characteristics and knowledge of patients

\begin{tabular}{|c|c|c|c|c|c|c|}
\hline \multirow[t]{2}{*}{ Characteristic } & \multirow[b]{2}{*}{$N(530)$} & \multirow[b]{2}{*}{$\%$} & \multicolumn{2}{|c|}{ Hospital physician } & \multicolumn{2}{|c|}{ Discharge form } \\
\hline & & & $\mathrm{N}$ & $\%$ & $\mathrm{~N}$ & $\%$ \\
\hline \multicolumn{7}{|l|}{ Sex } \\
\hline Male & 302 & 57 & 188 & 62.2 & 114 & 37.8 \\
\hline \multirow[t]{2}{*}{ Female } & 228 & 43 & 171 & 75 & 57 & 25 \\
\hline & \multicolumn{6}{|c|}{$x^{2}=9.66,1 d f, p=0.002$} \\
\hline \multicolumn{7}{|l|}{ Age } \\
\hline \multirow[t]{2}{*}{ Mean \pm SD } & \multirow[t]{2}{*}{$63.3 \pm 13.7$} & & \multicolumn{2}{|c|}{$62.9 \pm 13.9$} & \multirow[t]{2}{*}{$64.1 \pm 13.3$} & \\
\hline & & & $t=0.87$ & 387 & & \\
\hline \multicolumn{7}{|l|}{ Marital status } \\
\hline Married & 410 & 77.4 & 278 & 67.8 & 132 & 32.2 \\
\hline \multirow[t]{2}{*}{ Other } & 120 & 22.6 & 81 & 67.5 & 39 & 32.5 \\
\hline & \multicolumn{6}{|c|}{$x^{2}=0.004,1 \mathrm{df}, p=0.950$} \\
\hline \multicolumn{7}{|l|}{ Education level, years of schooling } \\
\hline None & 53 & 10 & 32 & 60.4 & 21 & 39.6 \\
\hline 5 & 166 & 31.3 & 115 & 69.3 & 51 & 30.7 \\
\hline 8 & 183 & 34.5 & 120 & 65.6 & 63 & 34.4 \\
\hline \multirow[t]{2}{*}{$\geq 13$} & 128 & 24.2 & 92 & 71.9 & 36 & 28.1 \\
\hline & \multicolumn{6}{|c|}{$x^{2}=2.88,3 \mathrm{df}, p=0.410$} \\
\hline \multicolumn{7}{|l|}{ Working activity } \\
\hline Unemployed/ Retired & 407 & 76.8 & 273 & 67.1 & 134 & 32.9 \\
\hline Artisan/lower managerial & 69 & 13 & 46 & 66.7 & 23 & 33.3 \\
\hline \multirow[t]{2}{*}{ High professional and managerial } & 54 & 10.2 & 40 & 74.1 & 14 & 25.9 \\
\hline & \multicolumn{6}{|c|}{$x^{2}=1.11,2 d f, p=0.574$} \\
\hline \multicolumn{7}{|l|}{ Living condition } \\
\hline Alone & 40 & 7.5 & 28 & 70 & 12 & 30 \\
\hline \multirow[t]{2}{*}{ Other } & 490 & 92.5 & 331 & 67.5 & 159 & 32.5 \\
\hline & \multicolumn{6}{|c|}{$x^{2}=0.1,1 \mathrm{df}, p=0.750$} \\
\hline \multicolumn{7}{|l|}{ Academic hospital } \\
\hline Yes & 296 & 55.8 & 242 & 81.8 & 54 & 18.2 \\
\hline No & 234 & 44.2 & 117 & 50 & 117 & 50 \\
\hline & & & $x^{2}=60$ & .001 & & \\
\hline Discharge ward & & & & & & \\
\hline General medicine & 161 & 30.4 & 111 & 68.9 & 50 & 31.1 \\
\hline Specialistic care & 369 & 69.6 & 248 & 67.2 & 121 & 32.8 \\
\hline & & & $x^{2}=0.1$ & & & \\
\hline Number of new prescription drugs & & & & & & \\
\hline 1 & 197 & 37.2 & 145 & 73.6 & 52 & 26.4 \\
\hline$>1$ & 333 & 62.8 & 214 & 64.3 & 119 & 35.7 \\
\hline & & & $x^{2}=4.9$ & & & \\
\hline
\end{tabular}

Reported behavior about mode of administration of the new drug

Correct

527

Not correct
0
100.0 
Table 2 Distribution of source of information about the new prescription drug according to characteristics and knowledge of patients (Continued)

\begin{tabular}{|c|c|c|c|c|c|c|}
\hline \multirow[t]{2}{*}{ Characteristic } & \multirow[b]{2}{*}{$N(530)$} & \multirow[b]{2}{*}{$\%$} & \multicolumn{2}{|c|}{ Hospital physician } & \multicolumn{2}{|c|}{ Discharge form } \\
\hline & & & $\mathrm{N}$ & $\%$ & $\mathrm{~N}$ & $\%$ \\
\hline \multicolumn{7}{|c|}{ Reported behaviour about time of administration of new drug } \\
\hline Correct & 479 & 99.8 & & & & \\
\hline Not correct & 1 & 0.2 & & & & \\
\hline \multicolumn{7}{|c|}{ Knowledge about duration of treatment } \\
\hline Correct & 348 & 96.7 & 254 & 73 & 94 & 27 \\
\hline \multirow[t]{2}{*}{ Not correct } & 12 & 3.3 & 4 & 33.3 & 8 & 66.7 \\
\hline & \multicolumn{6}{|c|}{$x^{2}=8.98,1 \mathrm{df}, p=0.003$} \\
\hline \multicolumn{7}{|c|}{ Knowledge about behavior in case of having forgotten medication intake } \\
\hline Yes & 163 & 30.8 & 123 & 75.5 & 40 & 24.5 \\
\hline \multirow[t]{2}{*}{ No } & 367 & 69.2 & 236 & 64.3 & 131 & 35.7 \\
\hline & \multicolumn{6}{|c|}{$x^{2}=6.43,1 \mathrm{df}, p=0.011$} \\
\hline \multicolumn{7}{|c|}{ Knowledge about behaviour in case of having taken the wrong dose of medication } \\
\hline Yes & 127 & 24 & 100 & 78.7 & 27 & 21.3 \\
\hline \multirow[t]{2}{*}{ No } & 403 & 76 & 259 & 64.3 & 144 & 35.7 \\
\hline & \multicolumn{6}{|c|}{$x^{2}=9.25,1 \mathrm{df}, p=0.002$} \\
\hline \multicolumn{7}{|c|}{ Knowledge about possible side effects } \\
\hline Yes & 45 & 8.5 & 33 & 73.3 & 12 & 26.7 \\
\hline \multirow[t]{2}{*}{ No } & 485 & 91.5 & 326 & 67.2 & 159 & 32.8 \\
\hline & \multicolumn{6}{|c|}{$x^{2}=0.71,1 \mathrm{df}, p=0.401$} \\
\hline \multicolumn{7}{|c|}{ Favourite person to contact in case of doubt about therapy } \\
\hline PCP & 291 & 54.9 & 173 & 59.4 & 118 & 40.6 \\
\hline Hospital specialist & 205 & 38.7 & 167 & 81.5 & 38 & 18.5 \\
\hline \multirow[t]{2}{*}{ Private specialist } & 34 & 6.4 & 19 & 55.9 & 15 & 44.1 \\
\hline & \multicolumn{6}{|c|}{$x^{2}=29,2 d f, p=<0.001$} \\
\hline \multicolumn{7}{|c|}{ Need for more information about the new medication } \\
\hline Yes & 220 & 41.5 & 117 & 53.2 & 103 & 46.8 \\
\hline \multirow[t]{2}{*}{ No } & 310 & 58.5 & 242 & 78.1 & 68 & 21.9 \\
\hline & \multicolumn{6}{|c|}{$x^{2}=36.45,1 d f, p<0.001$} \\
\hline
\end{tabular}

The numbers that do not add to 530 are due to missing data for the variable

patients discharged from hospital had received counselling and that it was associated with knowledge on medications [24]; moreover Coleman et al. reported that discrepancies between prescribed medication and actual old patients' behaviour were also related to systemassociated factors, such as conflicting information from different informational sources [25]. Although alarming, this finding was not surprising; in a study conducted by some of us to evaluate the adaptability of the Joint Commission on Accreditation of Healthcare Organizations (JCAHO) and the Centers for Medicare \& Medicaid Services (CMS) quality indicators in our geographical area we found that rates regarding adherence to discharge instructions in heart failure patients, that is one of the patient safety indicators, was "noticeably intangible" [26], thus confirming low attention to counseling at discharge in our hospitals. The investigation of quality and extent of information provided to patients showed that counselling at discharge performed by hospital physicians on new prescribed therapies dealt mainly on the rationale, dosing, route and timing of medications administration, whereas potential problems and/or actions to take in presence of errors or side effects of medications were not discussed at discharge. This finding has already been reported, and the Authors highlighted that health care professionals are reluctant to discuss eventual problems related to medications, since they fear that this kind of information may represent a barrier to adherence [15]. However, patients may not be satisfied by the absence of this information, since they want to be informed about 
Table 3 Logistic regression model results

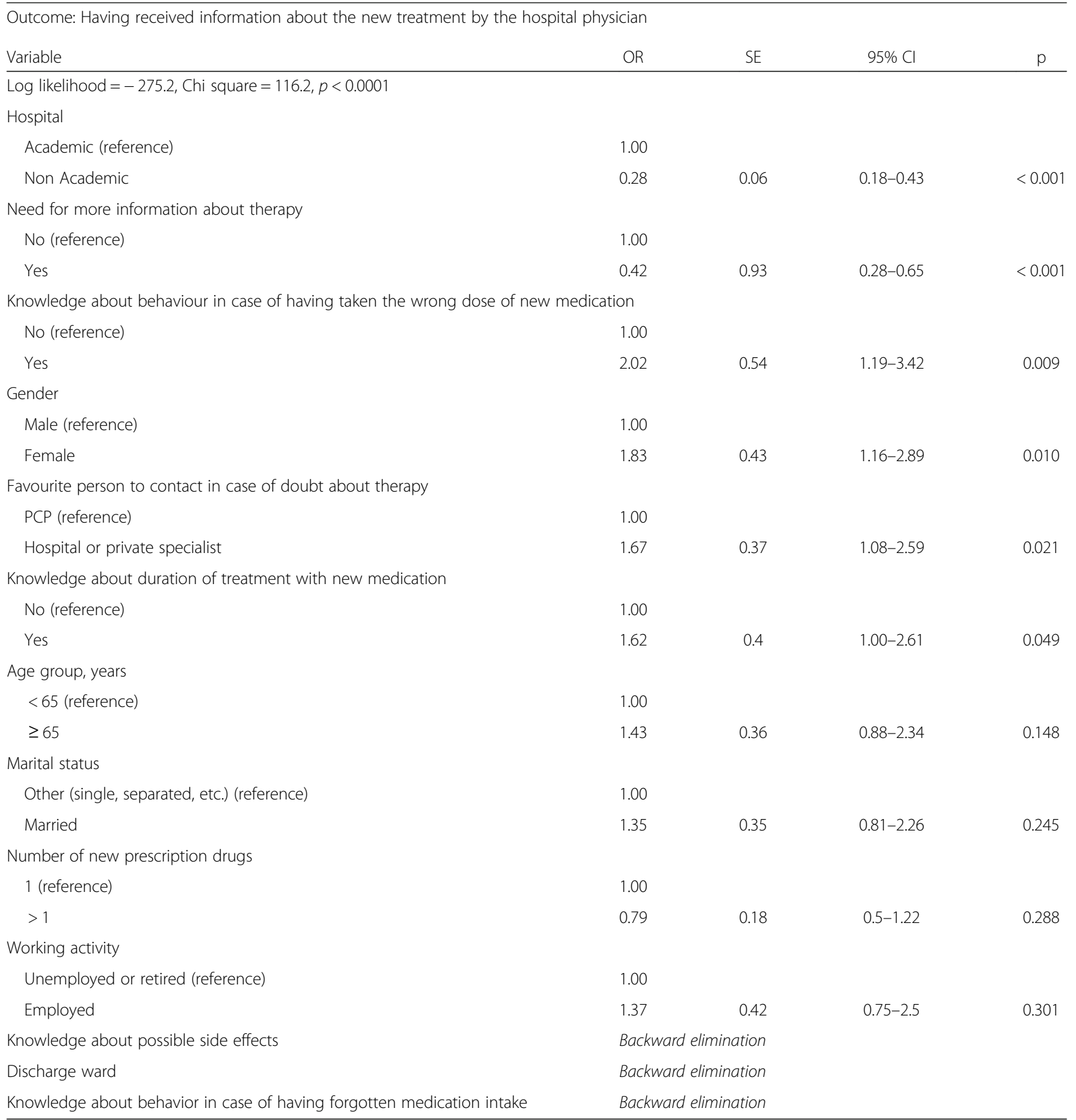

risks of medications $[17,22,27,28]$, and it has been reported that if patients are not satisfied about information received on prescribed therapies, there may be a negative impact on adherence to medications [29, 30, 31].

The second research question explored to what extent patients were aware and confident in the management of new prescribed medications and the findings of the study demonstrated that there is a very close agreement between the information provided and the self-confidence of patients, as well as a gap of knowledge in the areas that were not the object of counselling, such as drugs side effects or the behaviours to have if one forgets or takes wrong doses of the new drugs. This finding has been already reported by Thoren et al., who highlighted the risk that inadequate knowledge on these issues may limit the empowerment of patients representing a barrier to the autonomous management of therapies after discharge [24]. This is confirmed by our findings showing that even patients that feel confident on how to behave reported that they would refer to their PCP. 
The main finding of our study, exploring the hypothesis that the way communication is provided may affect patients' awareness and self-confidence in the management of new chronic drug therapies, showed that counselling by the hospital physician was significantly associated with higher knowledge and self-confidence. Although, as already discussed, the quality of counselling might be improved, our study demonstrated the effectiveness of the source of information for several aspect of knowledge, such as duration of therapy and behaviour to have in case of forgotten or wrong dose of drug taken. A certain degree of empowerment of patients was expressed by the finding that those who received information by the hospital physician significantly more frequently declared they did not need more information about the new prescribed drug, that was reported to be also the favourite person to contact in case of doubts about the therapy. Similar results have been reported by Micheli et al., who found that patients who had received information on long term therapies during hospitalization were significantly more likely to have knowledge about reasons for taking them [32], and Alkatheri et al., who reported that education level of patients and previous counselling were positively linked to medication knowledge [33]. Counselling was also associated to academic setting, but, since we evaluated only two hospitals, a cautious approach to the generalization of this finding is warranted, although it may be hypothesized that younger physicians, that attend their post graduate residency in the academic hospitals, may be more motivated since counselling to patients is among the learning goals of their training process. The only patient-related characteristic that showed to be associated to information provided by physician was female sex. We did not explore whether counselling was spontaneously administered by physicians or it was at request of the patient; however, since from previous research we have indirectly found that women are more concerned about their health, since they rated their health less satisfactory compared to men [34], and were more likely to use internet for health related issues [35], we may only hypothesize that they were more likely to stimulate hospital physicians to provide more detailed information about new prescribed drugs.

In a study assessing satisfaction on information about medicines provided to cardiac patients during hospitalization, the Authors could not discern whether written or in-person information was more effective [15], whereas in our study the peculiar Italian discharge process that includes a discharge form addressed to PCPs allowed us to assess that when written information is supplemented with physician-patient counseling the resulting patients' medication knowledge is significantly increased.
It is well-known that the hospital discharge process represent a crucial step for the potential consequences in the management of chronic patients in other healthcare settings. Our results clearly indicate that the discharge form as the only tool to inform patients about new medications is absolutely inadequate, and that counselling by physicians significantly improves patients' knowledge and self-confidence. It seems therefore useful to promote in our context a more extensive involvement of other hospital professional figures, such as nurses and pharmacists in the delicate discharge process of chronic patients.

\section{Limitations}

Some potential limitations of the present study need to be acknowledged. We collected data in two hospitals and concern about generalizability of our results may arise. However, although we cannot exclude that our results pertain only to our area, we may be quite confident that the context we have studied may be generalized at least to the Southern Italy hospitals. Moreover, data were based on medical record documentation and on patients self-reporting; however, we do not think that method of data collection may represent a problem in this case because self-reporting is the only way to collect information about knowledge and self-confidence in the management of drug prescriptions. Third, as is the case of all surveys, another limitation is the potential recall bias; nonetheless this was a minor issue considering the restricted 3 weeks period between discharge and telephone interview. It should also be noted, however, that the $95 \%$ response rate was extremely satisfactory and reduces one major potential source of bias in the results, that is sample representativeness. Finally, we used selfreported knowledge on several aspects of new prescribed drugs as an indicator of effective communication at discharge and as a prerequisite for effective adherence to prescribed therapies, whereas we did not directly explore communication strategies performed by physicians, nor actual adherence to treatments.

\section{Conclusions}

In conclusion, our results have demonstrated that several aspects of patients' knowledge and selfconfidence on long term medications prescribed at hospital discharge need to be improved and that the way communication is provided has a crucial role in the empowerment of patients in the management of these medications. Since adequate knowledge has been related to adherence to medications, efforts are needed to select and introduce in the hospital settings effective communication and counseling strategies. 


\section{Abbreviations}

Cl: Confidence interval; CMS: Center for Medicare \& Medicaid Services; JCAHO: Joint Commission on Accreditation of Healthcare Organizations; OR: Odds ratio; PCP: Primary care physician

\section{Acknowledgements}

The Authors would like to thank Dr. Ashour Michael for having checked the English in this manuscript.

\section{Funding}

None.

\section{Availability of data and materials}

The data collected and analyzed are not publicly available because of confidentiality concerns due to the nature of the study. However, all relevant and supporting data are contained within the manuscript.

\section{Authors' contributions}

CP participated in the conception and design of the study, collected the data, contributed to the data analysis and its interpretation, and wrote the first draft of the article. EC and CGAN collected the data, and contributed to the data analysis and interpretation. MP designed the study, was responsible for the data analysis and interpretation, and wrote the article. CP and MP are guarantors for the study. All authors had full access to all of the data (including statistical reports and tables) in the study and can take responsibility for the integrity of the data and the accuracy of the data analysis. All authors read and approved the final manuscript.

\section{Ethics approval and consent to participate}

The study protocol was approved by the Ethics Committee of the "Mater Domini" Hospital of Catanzaro (Italy) (15/12/2011).

Written informed consent to participate in the study has been obtained from all participants.

\section{Consent for publication}

Not applicable, as the manuscript does not contain any individually identifiable person's data.

\section{Competing interests}

The authors declare that they have no competing interests.

\section{Publisher's Note}

Springer Nature remains neutral with regard to jurisdictional claims in published maps and institutional affiliations.

\section{Author details}

'Department of Health Sciences, University of Catanzaro "Magna Græcia", Via Tommaso Campanella, 88100 Catanzaro, Italy. ${ }^{2}$ Department of Pharmacy, Health and Nutritional Sciences, University of Calabria, Arcavacata di Rende, 87036 Cosenza, Italy.

Received: 7 January 2016 Accepted: 29 January 2018

Published online: 12 February 2018

\section{References}

1. WHO (2002) Innovative Care for Chronic Conditions: Building Blocks for Action. Geneva: World Health Organization. Available at: http://www.who. int/chp/knowledge/publications/icccglobalreport.pdf. Accessed 4 Nov 2016.

2. Bodenheimer T, Wagner EH, Grumbach K. Improving primary care for patients with chronic illness: the chronic care model, part 2. JAMA. 2002; 288:1909-14.

3. Weingarten SR, Henning JM, Badamgarav E, et al. Interventions used in disease management programmes for patients with chronic illness: which ones work? Meta-analysis of published reports. BMJ. 2002;325:925.

4. Ouwens $M$, Wollersheim H, Hermens R, Hulscher M, Grol R. Integrated care programmes for chronically ill patients: a review of systematic reviews. Int J Qual Health Care. 2005;17:141-6.

5. Singh, D. Transforming chronic care. Evidence about Improving Care for People with Long-term Conditions. Birmingham: University of Birmingham Surrey and Sussex PCT Alliance, 2005. Available at: http://www.download. bham.ac.uk/hsmc/pdf/transforming_chronic_care.pdf. Accessed 9 Nov 2016.
6. Singh D, and Ham C. (2006) Improving Care for People with long-term conditions. A review of UK and international frameworks. Birmingham: University of Birmingham, NHS Institute for Innovation and Improvement. Available at http://www.improvingchroniccare.org/downloads/review_of_ international_frameworks_chris_hamm.pdf. Accessed 9 Nov 2016.

7. Wagner EH, Davis C, Schaefer J, Von Korff M, Austin B. A survey of leading chronic disease management programs: are they consistent with the literature? Manage Care Q. 1999;7:56-66.

8. WHO (2003) Adherence to long-term therapies. Evidence for Action. Geneva: World Health Organization. Available at: http://apps.who.int/iris/ bitstream/10665/42682/1/9241545992.pdf. Accessed 9 Nov 2016.

9. Vincent CA, Coulter A. Patient safety: what about the patient? Qual Saf Health Care. 2002;11:76-80.

10. Agenzia Nazionale per i Servizi Regionali - Age.Na.S. (2005): Identificazione, sperimentazione e validazione di alcuni indicatori di processo ed esito della qualità delle attività sanitarie. Rapporto conclusivo. Available at: http://www agenas.it/images/agenas/monitor/quaderno/pdf/1_INDICATORI_QUALITA. pdf. Accessed 17 June 2014.

11. Joint Commission on Accreditation of Healthcare Organizations. 2015. Specifications Manual for National Hospital Inpatient Quality Measures. Version 4.4a. Available at: http://www.qualitynet.org/dcs/ContentServer?c= Page\&pagename $=$ QnetPublic\%2FPage\%2FQnetTier3\&cid $=1228773989482$ Accessed 8 June 2015

12. Agency for Healthcare Research and Quality. 2014. Quality Indicator Empirical Methods. Revised November 2014. Rockville, MD:. Available at: http://www.qualityindicators.ahrq.gov/Downloads/Resources/Publications/ 2015/Empirical_Methods_2015.pdf. Accessed 8 June 2015.

13. Agency for Healthcare Research and Quality. Center for Health Policy/Center for Primary Care and Outcomes Research \& Battelle Memorial Institute. 2011. Quality Indicator Measure Development, Implementation, Maintenance, and Retirement. Available at: http://www.qualityindicators.ahrq.gov/Downloads/ Resources/Publications/2011/QI Measure_Development_Implementation Maintenance_Retirement_Full_5-3-11.pdf. Accessed 17 June 2014

14. Fallis BA, Dhalla IA, Klemensberg J, Bell CM. Primary medication nonadherence after discharge from a general internal medicine service. PLoS One. 2013:8:e61735

15. Auyeung V, Patel G, McRobbie D, Weinman J, Davies G. Information about medicines to cardiac in-patients: patient satisfaction alongside the role perceptions and practices of doctors, nurses and pharmacists. Patient Educ Couns. 2011:83:360-6.

16. Lisper L, Isacson D, Sjoden P, Bingefors K. Medicated hypertensive patients' views and experience of information and communication concerning antihypertensive drugs. Patient Educ Couns. 1997;32:147-55.

17. Schneider A, Wensing M, Quinzler R, Bieber C, Szecsenyi J. Higher preference for participation in treatment decisions is associated with lower medication adherence in asthma patients. Patient Educ Couns. 2007;67:57-62

18. Street RL, Howard GH, Haidet P. Physicians' communication and perceptions of patients: is it how they look, how they talk, or is it just the doctor? Soc Sci Med. 2007:65:586-98.

19. McDonald H, Garg AX, Haynes RB. Interventions to enhance patient adherence to medication prescriptions. Scientific review. JAMA. 2002;288:2868-79.

20. Okere AN, Renier CM, Morse J. Development and validation of a survey to assess patient-perceived medication knowledge and confidence in medication use. J Nurs Meas. 2014;22:1-13.

21. Stata Corporation: 2009, Stata Statistical Software: Release 11 College Station, TX, USA. StataCorp LP.

22. Nair K, Dolovich L, Cassels A, et al. What patients want to know about their medications. Focus group study of patient and clinician perspectives. Can Fam Physician. 2002;48:104-10.

23. Law AV, Ray MD, Knapp KK, et al. Unmet needs in the medication use process: perceptions of physicians, pharmacists, and patients. J Am Pharm Assoc. 2003:43:394-402.

24. Toren O, Kerzman H, Koren N, Baron-Epel O. Patients' knowledge regarding medication therapy and the association with health services utilization. Eur $J$ Cardiovasc Nurs. 2006;5:311-6.

25. Coleman EA, Smith JD, Raha D, Min SJ. Posthospital medication discrepancies: prevalence and contributing factors. Arch Intern Med. 2005 165:1842-7.

26. Flotta D, Rizza P, Coscarelli P, Pileggi C, Nobile CG, Pavia M. Appraising hospital performance by using the JCHAO/CMS quality measures in southern Italy. PLoS One. 2012;7:e48923. 
27. Berry DC, Michas IC, Gillie T, Forster M. What do patients want to know about their medicines, and what do doctors want to tell them?: a comparative study. Psychol Health. 1997:4:467-80.

28. Ziegler DK, Mosier MC, Buenaver M, Okuyemi K. How much information about adverse effects of medication do patients want from physicians? Arch Intern Med. 2001;161:706-13.

29. Horne R, Hankins M, Jenkins R. The satisfaction with information about medicines scale (SIMS): a new measurement tool for audit and research. Qual Health Care. 2001;10:135-40.

30. Aikens JE, Piette JD. Diabetic patients' medication underuse, illness outcomes, and beliefs about antihyperglycemic and antihypertensive treatments. Diabetes Care. 2009;32:19-24.

31. Bowskill R, Clatworthy J, Parham R, Rank T, Horne R. Patients' perceptions of information received about medication prescribed for bipolar disorder: implications for informed choice. J Affect Disord. 2007:100:253-7.

32. Micheli P, Kossovsky MP, Gerstel E, et al. Patients' knowledge of drug treatments after hospitalisation: the key role of information. Swiss Med Wkly. 2007;137:614-20

33. Alkatheri AM, Albekairy AM. Does the patients' educational level and previous counseling affect their medication knowledge? Ann Thorac Med. 2013;8:105-8.

34. Manuti B, Rizza P, Pileggi C, Bianco A, Pavia M. Assessment of perceived health status among primary care patients in southern Italy: findings from a cross-sectional survey. Health Qual Life Outcomes. 2013;11:93.

35. Bianco A, Zucco R, Nobile CGA, Pileggi C, Pavia M. Parents seeking healthrelated information on the internet: cross-sectional study. J Med Internet Res. 2013;15:e204.

\section{Submit your next manuscript to BioMed Central and we will help you at every step:}

- We accept pre-submission inquiries

- Our selector tool helps you to find the most relevant journal

- We provide round the clock customer support

- Convenient online submission

- Thorough peer review

- Inclusion in PubMed and all major indexing services

- Maximum visibility for your research

Submit your manuscript at www.biomedcentral.com/submit
Biomed Central 